Original Research Article

\title{
Adverse drug reactions associated with first line anti-tubercular drugs, their prevalence and causality assessment in patients on Directly Observed Treatment Short-course (DOTS) in a tertiary care hospital
}

\author{
Tauseef Nazir*, Sameena Farhat, Mohd Adil, Zuryat Asraf
}

Department of Pharmacology, GMC, Srinagar, Jammu and Kashmir, India

Received: 30 October 2018 Accepted: 29 November 2018

*Correspondence to:

Dr. Tauseef Nazir,

Email: tauseefnazir@yahoo.com

Copyright: (C) the author(s), publisher and licensee Medip Academy. This is an openaccess article distributed under the terms of the Creative Commons Attribution NonCommercial License, which permits unrestricted noncommercial use, distribution, and reproduction in any medium, provided the original work is properly cited.

\begin{abstract}
Background: Treatment of tuberculosis involves giving multiple drugs to the patient which is done to prevent development of resistance besides targeting all bacterial sub-populations. The objective of the present study was to find out the adverse drug reactions (ADRs) of the first line anti-tubercular drugs and to calculate prevalence and causality of these drugs.

Methods: The study was conducted by the Department of Pharmacology, Government Medical College, Srinagar in association with the department of Chest medicine. All patients of tuberculosis on directly observed treatment-short course (DOTS) of either sex or age group were enrolled. An assessment of the causality and allocation of ADRs was done using Naranjo's monitoring scale and WHO-UMC scale.

Results: A total of 57 ADRs with 13 different types were observed in 164 patients, with an overall prevalence of about $34.7 \%$. Thirty seven (64.9\%) ADRs were categorized as having a 'probable' causal relationship while 17 (29.8\%) was categorized as 'possible' as per the Naranjo's scale. As per the WHO-UMC monitoring scale fifty two $(91.2 \%)$ were categorized as 'possible' while three $(5.3 \%)$ were categorized as 'certain'.

Conclusions: Occurrence of ADRs generally results in non-adherance. Timely detection of ADRs through an effective pharmacovigilance programme is the need of hour. The establishment of an active pharmacovigilance centre which was set up in our institution has paved the way to improve the quality of patient care by ensuring safer use of drugs and has helped us to identify and report the various ADR's encountered.
\end{abstract}

Keywords: Adverse drug reactions, DOTS, Tuberculosis, WHO-UMC

\section{INTRODUCTION}

Adverse drug reactions (ADR) usually referred to as a noxious and unintended response to a drug occurring at doses normally used in humans for the prophylaxis, diagnosis and treatment of disease or for modification of physiological function can be a potential factor leading to treatment non -adherence due to increased patient suffering and incur of additional costs because of increased outpatients visits, tests and in more serious instances hospitilizations. ${ }^{1,2}$
Adverse drug reactions adversely affect the quality of life of patients, cause them to lose confidence in their doctors, increase the costs of healthcare, preclude the use of drugs in most patients, resulting in unnecessary investigations and delay in the treatment. ${ }^{3,4}$ Adverse drug reactions have been seen to cause 1 out of 5 injuries or deaths per year to hospitalized patients whereas mean length of stay, cost and mortality for ADR patients are double than that for control patients. ${ }^{5}$ In relation to mortality a landmark meta-analysis of 39 prospective studies conducted by Lazarou et al, found that Adverse drug reactions resulting in medical management were the fourth to sixth highest cause of death 
in emergency services in United States, following only ischemic cardiopathy, cancer and stroke. ${ }^{6,7}$

Data suggests that One-fourth of the world's population is thought to have been infected with M. Tuberculosis In 2017, about 10 million people around the world became sick with $\mathrm{TB}$ resulting in 1.3 million TB-related deaths worldwide. $^{8}$

The rate of tuberculosis in different areas varies across the globe; about $80 \%$ of the population in many Asian and African countries test positive in tuberculin tests while only $5-10 \%$ of the United States population test positive, the reason being attributed to a poor immune system largely due to high rates of HIV infection and the corresponding development of AIDS in the developing countries. ${ }^{9,10}$

The standard anti-TB short course chemotherapy regimen comprised of taking drug combinations of isoniazid, rifampicin, pyrazinamide, ethambutol and /or streptomycin for a period 6-9months.

The WHO has recommended DOTS to be an effective treatment strategy for detection and cure of $\mathrm{TB}$ and for controlling the TB epidemic today. Pharmacotherapy of TB consists of giving drug combinations to increase the effectiveness and decrease the emergence of drug resistance. But more the number of drugs, adverse effects are added up too. Incidence of adverse drug reaction's (ADR) being high with these drugs is resulting in more dropouts, change of regime and inadequate or incomplete treatment, all these contributing to emergence of multidrug resistant (MDR) and extensive drug-resistant cases (XDR) strains increasing the morbidity and mortality. ${ }^{11}$ Though none of the anti- tuberculosis drug is without adverse reactions but only rarely are the adverse reactions life threatening

Objectives of the present study are to find out the prevalence of adverse drug reactions (ADRs) of the antitubercular drugs in patients of tuberculosis on Directly Observed Treatment- Short course (DOTS). And to find out the causality of adverse drug reactions using WHOUppsala Monitoring Centre and Naranjo's scale (WHOUPC) scale.

\section{METHODS}

The present study was observational longitudinal. After getting approval from the Institutional Ethics Committee, the study was conducted by the Department of Pharmacology in association with the Department of Chest Medicine, Government Medical College (GMC), Srinagar over the period of a one and a half year commencing on $1^{\text {st }}$ April 2016.

The patients coming to the DOTS centre of GMC and associated hospital were studied. The participants were provided with explicit explanation for their inclusion in the study by instituting written informed consent duly translated in local Vernacular.

\section{Inclusion criteria}

All patients diagnosed with tuberculosis (pulmonary, extra-pulmonary) on DOTS with first line drugs during study period.

\section{Exclusion criteria}

- Patients refusing to give consent for the study

- Patients taking ATT which includes drugs other than first line anti-tubercular drugs

- Patients with underlying organ disease or patients with co-infection like HIV, hepatitis B and hepatitis C.

\section{Handling of ADR reports}

Adverse drug reactions (ADRs) were reported spontaneously by patients/ their guardians or the reporting doctor and a questionnaire (active surveillance) was used asking the patient specific questions related to likely ADRs and patient's responses were recorded in the case record form. Once the ADR reports were detected/collected and prepared in consultation with doctors, nurses and pharmacists on duty in OPD, they were scrutinized to prevent any kind of reporting bias on part of investigator.

\section{Causality assessment}

Following criteria was used for establishing causal relationship between drug administration and an ADR:

- A temporal (time related) relationship between suspected drug and ADR.

- Improvement after withdrawal of the drug i.e. positive dechallenge.

- A previous exposure to the same suspected drug i.e. pre-challenge.

- The lack of confounding effect t i.e. ADR unlikely to be due to concomitant diseases or due to some other previously consumed medicines.

\section{Based on above mentioned criteria, ADRs were classified as under}

\section{Definite}

Wherein ADR followed a reasonable temporal sequence from administration of the drug and was confirmed by positive dechallenge or positive rechallenge.

\section{Probable}

Wherein ADR followed a reasonable temporal sequence from administration of the drug, was confirmed by dechallenge but was not reasonably explained by the known characterization of patient's clinical state. 


\section{Possible}

Wherein ADR followed a reasonable temporal sequence from administration of the drug and followed a known response pattern to the suspected drug but could also have been produced by the patient's clinical state or other modes of therapy administered to the patient.

\section{Doubtful}

ADR that did not meet the above-mentioned criteria especially if the ADR had no temporal association with the drug use.

On the basis of causality assessment done as above patients were classified into following 3 groups:

- Patients without ADR (either at the time of admission or during hospitalization).

- Patients with ADRs at admission including patients admitted because of ADRs and patients with ADRs which the cause of hospital admission were not.

- Patients with ADRs occurring during their hospital stay.

An assessment of the causality and allocation of ADRs to these different categories was done using Naranjo's monitoring scale and WHO-UMC scale. ${ }^{12,13}$

\section{Statistical analysis}

Data was entered in Microsoft Excel. Continuous data was summarized as mean $( \pm)$ standard deviation or the five number summary as appropriate. Categorical variables were summarized as percentages. Chi-square test was used to test for independence of two categorical variables. Bar charts and pie charts were used for graphical presentation of data.

\section{RESULTS}

Table 1 signifies the distribution of the study population according to presence/absence of any ADR. Total 164 patients were enrolled in present study. Out of 164 patients, 57 patients reported ADRs, while as 107 patients did not develop ant type of ADRs during the study period. Overall prevalence of ADRs was $34.80 \%$ as per present study.

Table 1: Distribution of study population according to ADR.

\begin{tabular}{|lll|}
\hline ADR & Frequency & Percentage \\
\hline Present & 57 & 34.8 \\
\hline Absent & 107 & 65.2 \\
\hline Total & 164 & 100 \\
\hline
\end{tabular}

Table 2 shows distribution of the patients in patients presenting with ADRs as per the gender. Out of 57 patients presenting with ADRs, 35 of them were males while as 22 patients were females. There was statistically significant $(\mathrm{p}=0.0006)$ relationship between gender and the proportion of the ADRs with $49.3 \%$ of males showing ADRs while only $23.7 \%$ of the females had ADRs.

Table 2: Distribution and association of ADR with gender in studied population.

\begin{tabular}{|lllllll|}
\multirow{2}{*}{ Gender } & \multicolumn{2}{c}{ ADR present } & \multicolumn{2}{c|}{ ADR absent } & \multirow{2}{*}{ Total } \\
& No. & \%age & No. & \% age & \\
\hline Male & 35 & 49.3 & 36 & 50.7 & 71 \\
\hline Female & 22 & 23.7 & 71 & 76.3 & 93 \\
\hline Total & 57 & 34.8 & 107 & 65.2 & 164 \\
\hline
\end{tabular}

Chi-square $=11.672 ;$ P-value $=0.0006$ (Significant)

Table 3: Distribution of patients presenting with ADR's as per weight.

\begin{tabular}{|ll|l|}
\hline Weight (kgs) & Frequency & Percentage \\
\hline Maj $\leq 20$ & 4 & 7.0 \\
\hline $21-40$ & 3 & 5.3 \\
\hline $41-60$ & 30 & 52.6 \\
\hline$>60$ & 20 & 35.1 \\
\hline Total & 57 & 100 \\
\hline
\end{tabular}

Table 3 shows the distribution of the patients presenting with ADR's according to the body weight in kilograms (kgs). Majority of the patients $(52.6 \%)$ presenting with ADRs were having body weight between $41-60 \mathrm{kgs}$, followed by $35.1 \%$ in patients having weight of more than $60 \mathrm{kgs}$. Further $7 \%$ patients had weight of less than $20 \mathrm{kgs}$ while $5.3 \%$ were having a body weight between $21-40 \mathrm{kgs}$.

Table 4: Most common type of ADR's.

\begin{tabular}{|llll|}
\hline Type of ADR & & Frequency & \% \\
\hline \multirow{2}{*}{ Gastrointestinal } & $\begin{array}{l}\text { Decreased } \\
\text { appetite }\end{array}$ & 16 & 28.1 \\
\cline { 2 - 4 } & Nausea/vomiting & 13 & 22.8 \\
\hline \multirow{2}{*}{ Dermatological } & Itching & 5 & 8.8 \\
\cline { 2 - 4 } & Rash & 2 & 3.5 \\
\hline Skelton system & Joint pain & 5 & 8.8 \\
\hline \multirow{2}{*}{ Liver } & $\begin{array}{l}\text { Drug induced } \\
\text { liver injury }\end{array}$ & 3 & 5.3 \\
\hline \multirow{2}{*}{ Renal system } & $\begin{array}{l}\text { Acute kidney } \\
\text { injury }\end{array}$ & 1 & 1.8 \\
\hline \multirow{2}{*}{$\begin{array}{l}\text { Nervous } \\
\text { system }\end{array}$} & Increased sleep & 2 & 3.5 \\
\cline { 2 - 4 } & $\begin{array}{l}\text { Peripheral } \\
\text { neuropathy }\end{array}$ & 2 & 3.5 \\
\hline \multirow{2}{*}{ Others } & $\begin{array}{l}\text { Increased serum } \\
\text { uric acid }\end{array}$ & 1 & 1.8 \\
\cline { 2 - 4 } & $\begin{array}{l}\text { Metallic taste in } \\
\text { mouth }\end{array}$ & 3 & 5.3 \\
\cline { 2 - 4 } & Flank pain & 2 & 3.5 \\
\cline { 2 - 4 } & Pain calf muscle & 2 & 3.5 \\
\hline
\end{tabular}


Table 4 indicates the different types of ADRs reported by studied population. A total of 13 different types of ADRs were reported in the study population. The most common ADR was loss of appetite $(28.07 \%)$ followed by nausea/vomiting (22.8\%), itching and arthralgia each in $8.8 \%$, drug induced liver injury and metallic taste in mouth each in $5.3 \%$. Somnolence, flank pain, rash, peripheral neuropathy and pain in the calf muscle were reported in $3.50 \%$ of the patients each. Acute kidney injury and hyperuricemia were reported in $1.75 \%$ of the patients each.

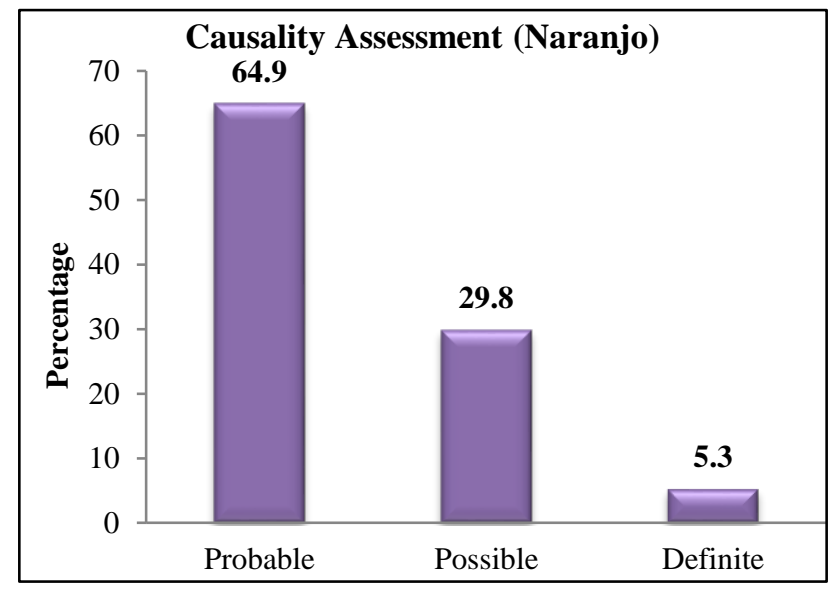

Figure 1: Causality assessment (Naranjo).

Out of a total 57 ADRs, thirty seven (64.9\%) were categorized as having a probable casual relationship with the anti-tuberculosis drugs as per the Naranjo's scale and seventeen $(29.8 \%)$ were categorized as possible as per the Naranjo's scale. Also, three (5.3\%) were categorized as definite. The three patients who were categorized as definite were diagnosed as drug induced liver injury (DILI). The suspicious drugs were stopped, and rechallenge was done (Figure 1).

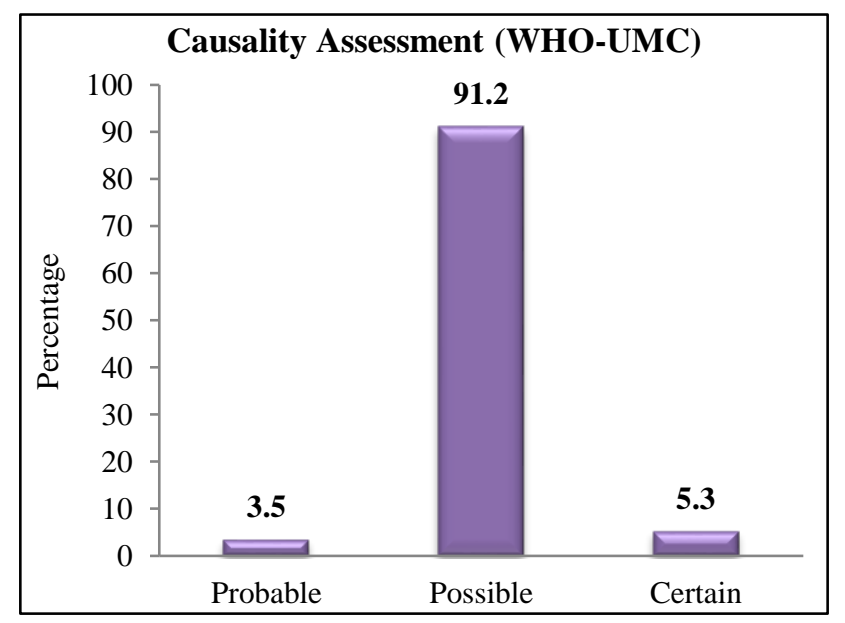

Figure 2: Causality assessment (WHO-UMC).

As per the WHO-UMC Scale for assessing causality of ADR's, two (3.5\%) ADRs were classified as probable, fifty two $(91.2 \%)$ were classified as possible and three $(5.3 \%)$ were classified as certain (Figure 2).
Table 5 shows duration in weeks at which ADRs presented after the initiation of ATT. Fifty five (96.50\%) of the ADRs were reported during intensive phase and only $3.50 \%$ of ADRs were reported during continuation phase. As minimum four drugs are used during intensive phase there are increased chances of the development of the ADRs during this phase.

Table 5: Duration (in weeks) at which ADR presented from start of treatment.

\begin{tabular}{|lll|}
\hline Week & Frequency & Percentage \\
\hline First & 13 & 22.8 \\
\hline Second & 17 & 29.8 \\
\hline Third & 9 & 15.8 \\
\hline Fourth & 10 & 17.5 \\
\hline Fifth & 3 & 5.3 \\
\hline Sixth & 1 & 1.8 \\
\hline Seventh & 0 & 0.0 \\
\hline Eighth & 2 & 3.5 \\
\hline Ninth & 1 & 1.8 \\
\hline Twenty Fourth & 1 & 1.8 \\
\hline Total & 57 & 100 \\
\hline
\end{tabular}

\section{DISCUSSION}

Tuberculosis, an infectious disease caused by mycobacterium tuberculosis, is the second most leading cause of death (after cardiovascular diseases) in the world. The World Health Organisation (WHO) declared TB as a global emergency in 1996.TB remains as a major health public health problem in India. India accounts for one-fifth of the global TB incident cases and topping the list among high burden countries. It is estimated that annually around 330,000 Indians die due to TB.

As the drug combinations used for the treatment of Tuberculosis are used for a prolonged period of time, it is likely that the ADRs of one drug are potentiated by the other drugs used in the combination. All anti-tubercular drugs can produce ADRs and involve almost all systems in the body such as gastro-intestinal tract, liver, skin, nervous system, vestibular apparatus and eyes. The adverse drug reactions to the drugs are one of the major reasons for the patients to default from the treatment. ADRs not only contribute to the non-compliance to the therapy but may also occasionally lead to the stoppage of treatment due to their severity and thus lead to development of drug resistance strains. These resistant strains require second line drugs for treatment which have higher cost and more serious adverse drug reactions. ADRs mostly tend to occur in the first three months of treatment. ${ }^{14}$

The present study was conducted by the department of pharmacology in collaboration with the department of chest medicine, Government Medical College, Srinagar between April 2016 to September 2017 to study the side effect profile of first line anti-tuberculosis drugs on directly observed treatment short course (DOTs) and assess their 
severity and causality. The proportion of patients with at least one ADR was found to be $34.7 \%$ and most of them $77.20 \%$ being mild in severity. As per the Naranjo's monitoring scale, $94.7 \%$ had a probable/possible and $5.3 \%$ had definite causal relationship with anti-tuberculosis drugs; the corresponding figure as per the WHO-UMC scale was almost the same.

Present study was an observational study with bi-weekly follow up during the intensive phase and bi-monthly follow up during the continuation phase. A total of 164 patients were enrolled and followed during these periods that were treated with DOT's.

In present study the maximum number patients $(52.43 \%)$ had weight between 41-60 kilograms and the population used by Sinha et al, was similar to current study population as far as weight is concerned. In a Study done by Iyer et al, TB patients $(80 \%)$, weighed below average for Indian reference adult man $(60 \mathrm{~kg})$ and women $(50 \mathrm{~kg}) \cdot 1^{5,16}$ The overall prevalence of ADRs in present study was $34.7 \%$. A study conducted in a tertiary care hospital, Lahore, Pakistan by Aamir et al, reported similar findings with incidence of $40.2 \% .{ }^{17}$ Similar results have also been reported by Hassan et al. ${ }^{18} \mathrm{~A}$ study conducted in a tertiary care hospital, Manipal, India by Sinha et al, reported an ADR incidence of $69.01 \% .{ }^{15}$ Another survey in Malaysia reported an ADR incidence of $15.8 \%$; while a study done in Gujarat, India reported an incidence of $7.9 \% .^{19,20}$

One possible explanation of this variation could be differences in detecting methods of ADRs. As to whether ADRs were collected based on face to face interview with patients and chart review, or retrospectively from patient's medical records, besides genetic makeup could also have played a role.

Authors used both the WHO-UMC scale and Naranjo's monitoring scale for causality assessment. All the ADRs reported in the present study were causally related to the anti-tuberculosis drugs prescribed. Out of 57 ADRs, 37 $(65 \%)$ were categorised as having a probable causal relationship with the anti-tuberculosis drug while 17 $(29.7 \%)$ were categorised as possible as per the Naranjo's scale, further $3(5.3 \%)$ ADRs were categorised as definite. As per the WHO-UMC scale for assessing causality, 52 $(91.20 \%)$ ADRs were classified as possible, 2 (3.50\%) were classified as probable and $3(5.30 \%)$ were classified as certain. Ramanath et al, reported similar findings with most $(92.97 \%)$ ADRs showing a possible causal relationship. ${ }^{21}$ Similar results have been reported by Damasceno et al. ${ }^{22}$ Present study had three certain/definite $(5.30 \%)$ cases in which re-challenge was done and offending drug was found to be pyrazinamide. A study conducted by Verma et al, categorised $9.8 \%$ of the cases as definite/severe. ${ }^{11}$ In present study, the prevalence of ADRs was more common in males $(49.3 \%)$ as compared to females $(23.7 \%)$. Athira B et al, reported similar findings with highest numbers $(68.81 \%)$ of ADRs being observed in males. ${ }^{23}$ Similar results have also been reported by
Dedun et al, but there are some studies suggesting females to be at higher risk of developing more ADRs. ${ }^{20,24}$ It might be because they pass through life stages like pregnancy, menarche and menopause that has an impact on the drug response. ${ }^{25}$ Studies done by Aamir et al, and Hassan et al, also had found ADRs to occur more commonly in females than males. ${ }^{17,18}$

A total of 57 ADRS were noted among 164 patients enrolled in the study. The most common ADR presented were gastro-intestinal symptoms found in $(50.9 \%)$ of the cases. Allergic Skin manifestation in form of itching and pruritis were reported in $12.28 \%$, while as arthralgia was reported in $8.8 \%$ of the ADRs. Three ADRs (5.26\%), each of drug induced liver injury (DILI) and metallic taste in the mouth were reported in the study, followed by 2 ADRs each of flank pain, sleep, peripheral neuropathy and pain in calf muscles. A study done by Sinha et al, also reported the frequency of ADRs in form of gastro-intestinal symptoms was found in $(53.52 \%)$ of the patients while as ADRs related to skin manifestation was reported in $8.45 \%$ of the patients according to the same study. ${ }^{15}$ Similarly Athira et al, found that the majority of the ADRs were related to was gastro-intestinal tract, followed by skin reactions. ${ }^{23}$ Similar results have been reported by Sood et al, Hassan et al, and Sribaddana et al. ${ }^{18,26,27}$ However study done by Aamir et al, had reported joint pain as the most common ADR while as a study done by Kurniawati et al, found skin reactions as the most common ADRs. ${ }^{17,19}$ Another study done by Kheirollah et al, found that the most common ADR was hepatitis. $^{28}$

\section{CONCLUSION}

The occurrence of ADRs generally results in nonadherence and frequent dropouts which makes the treatment more complicated because of the development of resistance. Timely detection of ADRs through an effective pharmacovigilance programme is the need of hour. The establishment of an active pharmacovigilance centre which was set up in authors' institution has paved the way to improve the quality of patient care by ensuring safer use of drugs and has helped us to identify and report the various ADR's encountered. By monitoring the patients closely, the ADRs can often be avoidable by adjusting the doses or if required, the withdrawal of the particular drug causing them.

\section{Funding: No funding sources Conflict of interest: None declared \\ Ethical approval: The study was approved by the Institutional Ethics Committee}

\section{REFERENCES}

1. WHO. International drug monitoring- the role of the national centres. Tech Rep ser WHO. No.; 1972:498.

2. Sinha K, Izora T, Asoka W. Adverse drug reactions in tuberculosis patients due to directly observed 
treatment strategy therapy. J Assoc Chest Physicians. 2013;1(2):50-3.

3. Bates DW, Spell N, Cullen DJ, Burdick E, Laird N, Petersen LA, et al. The costs of adverse drug events in hospitalized patients. JAMA. 1997 Jan 22;277(4):30711.

4. Classen DC, Pestotnik SL, Evans RS, Lloyd JF, Burke JP. Adverse drug events in hospitalized patients: excess length of stay, extra costs, and attributable mortality. JAMA. 1997 Jan 22;277(4):301-6.

5. Edwards IR, Aronson JK. Adverse drug reactions: definitions, diagnosis, and management. Lancet. 2000 Oct 7;356(9237):1255-9.

6. Wiffen P, Gill M, Edwards J, Moore A. Adverse drug reactions in hospital patients. A systematic review of prospective and retrospective studies. Bandolier Extra. 2002;2:1-16.

7. Lazarou J, Pomeranz BH, Corey PN. Incidence of adverse drug reactions in hospitalized patients: a metaanalysis of prospective studies. JAMA. 1998 Apr $15 ; 279(15): 1200-5$.

8. Centres for disease control and prevention. Tuberculosis: Data and statistics; 2017. Available at: https://www.cdc.gov/tb/statistics/default.htm. Accessed 01 November 2018.

9. Kumar V, Abbas AK, Fausto N, Mitchell RN. Robbins Basic Pathology. $8^{\text {th }}$ ed. Saunders Elsevier; 2007;516522.

10. Raval AA, Goswami H, Parikh U, Shah P, Yadav KS. Extra-pulmonary tuberculosis at tertiary health care center: a review. J Infect Dis Lett. 2013 Jan 1;2(1):16.

11. Verma R, Gr M, Shrivastava AK, Pathak P. Adverse drug reactions associated with first-line antitubercular drugs in a tertiary care hospital of central India: a study of clinical presentations, causality, and severity. Asian J Pharm Clin Res. 2014;7(5):140-3.

12. Naranjo CA, Busto U, Sellers EM, Sandor P, Ruiz I, Roberts EA, et al. A method for estimating the probability of adverse drug reactions. Clin Pharmacol Therapeut. 1981 Aug 1;30(2):239-45.

13. WHO Handbook of resolutions and decisions of the world Health Assembly and Executive Board. $11^{\text {th }}$ ed. Geneva, World Health Organizations, 1971-72. WHA 20.51 .

14. Sharma A, Kansal D, Katoch K, Sharma PK, Bansal $\mathrm{R}$, Sharma T. Pattern of adverse drug reactions in new smear positive patients of pulmonary tuberculosis treated under directly observed treatment short course. Int J Basic Clin Pharmacol. 2017 Jan 5;5(4):1397-401.

15. Sinha K, Marak IT, Singh WA. Adverse drug reactions in tuberculosis patients due to directly observed treatment strategy therapy: Experience at an outpatient clinic of a teaching hospital in the city of Imphal, Manipur, India. J Assoc Chest Physicians. 2013 Jul 1;1(2):50.

16. Iyer SP, Umakumar K, Mahajan A. Impact of HIV Infection on Outcome of Abdominal Tuberculosis. Bombay Hospital J. 2008;50(4):553-9.
17. Nazir A, Imam SF, Shabbir I, Saleem S. Adverse Drug Reactions of First Line Anti-tuberculosis Drugs used in DOTS Implemented Setting in Lahore. Pakistan J Med Res. 2015 Oct 1;54(4):101.

18. Hassan MK, Siddique A, Karadiya RK, Chakraborty A. Incidence of Adverse Drug Reaction Among the Tuberculosis Patients Treated Under Directly Observed Treatment Short course (DOTS) Regimen in North India. Indian J Applied Res. 2016;6(7):598-600.

19. Kurniawati F, Sulaiman SA, Gillani SW. Adverse drug reactions of primary anti-tuberculosis drugs among tuberculosis patients treated in chest clinic. Int J Pharmacy Life Sci. 2012 Jan 1;3(1):1331-8.

20. Dedun AR, Borisagar GB, Solanki RN. Impact of adverse drug reaction of first line anti-tuberculous drugs on treatment outcome of tuberculosis under revised national tuberculosis control programme. Int $\mathbf{J}$ Adv Med. 2017 May 23;4(3):645-9.

21. Ramanath KV, Ramesh SA. Study of assessment of adverse drug reactions in Tuberculosis patients. Am J Pharmtech Res. 2012;2(2)

22. Damasceno GS, Guaraldo L, Engstrom EM, Theme Filha MM, Souza-Santos R, et al. Adverse reactions to antituberculosis drugs in Manguinhos, Rio de Janeiro, Brazil. Clinics. 2013;68(3):329-37.

23. Athira B, Manju CS, Jyothi E. A study on adverse drug reactions to first line antitubercular drugs in DOTS therapy. Int J Pharmacol Clin Sci. 2015;4:7-11.

24. Puavilai S, Timpatanapong P. Prospective study of cutaneous drug reactions. Med Assoc Thai. 1989;72(3):167-71.

25. Wilson K. Sex-related differences in drug disposition in man. Clinpharmacokinest. 1984;9(3):189-202.

26. Sood A, Bansal R, Sharma A, Himani H, Bhagra S, Kansal D. Profile of adverse drug reactions in patients on anti-tubercular drugs in a sub Himalayan rural tertiary care teaching hospital. Int J Res Med Sci. 2016 Dec 19;4(10):4465-71.

27. Siribaddana A, Dissanayake KS, Athukorala GP, Pathirathne H, Senevirathna KP, Upul BA, et al. Frequency of adverse effects of fixed dose combinations, in tuberculosis and there effects on treatment outcome. SAARC J Tuberculosis Lung Dis HIV/AIDS. 2009;12(2):8-12.

28. Gholami K, Kamali E, Hajiabdolbaghi M, Shalviri G. Evaluation of anti-tuberculosis induced adverse reactions in hospitalized patients. Pharmacy Practice. 2006 Jul;4(3):134.

Cite this article as: Nazir T, Farhat S, Adil M, Asraf $\mathrm{Z}$, Haque A. Adverse drug reactions associated with first line anti-tubercular drugs, their prevalence and causality assessment in patients on Directly Observed Treatment Short-course (DOTS) in a tertiary care hospital. Int J Basic Clin Pharmacol 2019;8:147-52. 